\title{
An evaluation of specialist mentoring for university students with autism spectrum disorders and mental health conditions
}

Article

Accepted Version

Lucas, R. and James, A. I. (2018) An evaluation of specialist mentoring for university students with autism spectrum disorders and mental health conditions. Journal of Autism and Developmental Disorders, 48 (3). pp. 694-707. ISSN 15733432 doi: https://doi.org/10.1007/s10803-017-3303-1 Available at https://centaur.reading.ac.uk/73899/

It is advisable to refer to the publisher's version if you intend to cite from the work. See Guidance on citing.

Published version at: http://rdcu.be/yUE3

To link to this article DOI: http://dx.doi.org/10.1007/s10803-017-3303-1

Publisher: Springer

All outputs in CentAUR are protected by Intellectual Property Rights law, including copyright law. Copyright and IPR is retained by the creators or other copyright holders. Terms and conditions for use of this material are defined in the End User Agreement.

www.reading.ac.uk/centaur 
Central Archive at the University of Reading

Reading's research outputs online 


\title{
An evaluation of specialist mentoring for university students with autism spectrum disorders and mental health conditions
}

\begin{abstract}
Mentoring is often recommended to universities as a way of supporting students with autism spectrum disorders (ASD) and/or mental health conditions (MHC), but there is little literature on optimising this support. We used mixed-methods to evaluate mentees' and mentors' experiences of a specialist mentoring programme.

Mentees experienced academic, social and emotional support, although subtle group differences emerged between students with ASD and MHC. The quality of the menteementor relationship was especially important. Mentors also reported benefits. Thematic analysis identified that effective mentoring requires a tailored partnership, which involves a personal relationship, empowerment, and building bridges into the university experience.

Mentoring can effectively support students with ASD and/or MHC, but this is highly dependent on the development of tailored mentee-mentor partnerships.
\end{abstract}




\section{Introduction}

The proportion of students at university with a declared disability, such as autism spectrum disorder (ASD), is increasing (Higher Education Statistics Agency, [HESA] 2016). However, university students with disabilities face numerous educational, social and independent living challenges. In the UK they are less likely to graduate, and those that do are less likely to achieve a first-class or upper secondclass $(2: 1)$ honours degree than their non-disabled peers. In 2012/13 academic year $62.8 \%$ of students with a social communication disorder/ASD graduated with a firstclass or upper second-class honours degree, compared to $66 \%$ of students with disabilities overall and $68.1 \%$ of undergraduate students without disabilities (Equality Change Unit, 2014). Students with disabilities are also less likely to be in employment six months after graduation; in $201418.5 \%$ of graduates with a social/ASD condition were unemployed compared with $7.2 \%$ of disabled graduates overall and $5.1 \%$ of non-disabled graduates (Association of Graduate Careers Advisory Services, 2016). In light of this, Student Finance England provides a Disabled Students' Allowance (DSA) to eligible students, which can cover the costs of specialist support. One type of support frequently stipulated is specialist mentoring; a one-to-one supportive relationship between a professional mentor and a student mentee, which aims to support the mentee's development at university.

Little guidance is available for university disability support teams regarding the optimal delivery of mentoring. The DSA assessment specifies the number of mentoring hours, but not the content of the sessions, and there is a dearth of relevant empirical literature. Further, at the time of this research changes to the DSA were in consideration (Department for Business, Innovation \& Skills, 2015a, 2015b), which had potential implications for the extent to which specialist mentoring support would be funded via the DSA and the way in which universities should provide this support (e.g. in-house, external, required qualifications for specialist mentors).

The current study therefore evaluates the effectiveness of a specialist university mentoring programme, and crucially examines the factors contributing to the mentoring process. The study focuses on mentoring for students with ASD and / or mental health conditions (MHC), and places importance on the perspectives of both mentees and mentors. A mixed methods approach, comprising questionnaires and interviews, is utilised to attain in-depth data on outcomes and process. 


\section{Autism spectrum disorders}

Autism spectrum disorder (ASD) is characterised by persistent impairments in social communication and interaction, as well as restricted or repetitive patterns of behaviour, interests or activities (American Psychological Association, 2013). The prevalence of ASD in the general population is around 1\% (Baird et al., 2006; Brugha et al., 2011; Elsabbagh et al., 2012) and university may be a viable prospect for those without cognitive impairment, i.e. around half of individuals with ASD (Centers for Disease Control and Prevention, 2009; Charman et al., 2011). In the 2014-2015 academic year over 2,600 first year UK domiciled undergraduate students had declared a clinically diagnosed social communication impairment, representing $0.46 \%$ of the undergraduate population (HESA, 2016). These figures are substantially higher than five years earlier; in the 2009-2010 academic year around 2,300 first year undergraduate students had declared a diagnosis of ASD $(0.14 \%$ of the undergraduate population). It is likely that the percentage will continue to increase due to the gradual rise in the prevalence of ASD (Centers for Disease Control and Prevention, 2014) which is partially attributable to increased identification of ASD (Fombonne \& Chakrabarti, 2001). Indeed, at present, $0.7-1.9 \%$ of university students may meet diagnostic criteria for ASD, but not have a clinical diagnosis (White, Ollendick, \& Bray, 2011).

Whilst some adults with ASD have the cognitive ability to meet the educational demands of university, ASD characteristics may still impact the university experience. For example, students with ASD may find large class sizes challenging, have reduced understanding of the hierarchy of teaching and support staff, and find last minute room and staff changes stressful and anxiety provoking (Beardon, Martin, \& Woolsey, 2009; Cai \& Richdale, 2016; Gelbar, Smith, \& Reichow, 2014; Van Hees, Moyson, \& Roeyers, 2015; White et al., 2016). These challenges may be aggravated by social-communication difficulties, such as inefficiency in adapting language use in different social situations, e.g. peers vs professors (Van Hees et al., 2015), and impaired understanding of non-verbal communication and non-literal language such as inferences, metaphor, irony, or humour (Dennis, Lazenby, \& Lockyer, 2001; Martin \& McDonald, 2004; White et al., 2016; Wu et al., 2014). These impairments may also impact the development of friendships and romantic relationships (Beardon et al., 2009; Cai \& Richdale, 2016; van Bergeijk, Klin, \& Volkmar, 2008; Van Hees et al., 2015). Furthermore, sensory issues (e.g. increased sensitivity to flickering lights, typing on keyboards) may reduce class attendance and concentration, as well as social interaction (Beardon et al., 2009; Cai \& Richdale, 2016; van Bergeijk et al., 2008; Van Hees et al., 2015). The difficulties students 
with ASD experience at university can result in feelings of loneliness, anxiety and depression (Cai \& Richdale, 2016; Gelbar et al., 2014; White et al., 2016).

Although there is a paucity of research on specialist mentoring provision for university students with ASD, recently Ames, McMorris, Alli, and Bebko (2015) conducted an evaluation of the mentoring provision at York University in Ontario, Canada. At the end of the 2011-2012 academic year, 12 mentees completed a questionnaire regarding their mentoring experience. Seven of these had met their mentor weekly and eight had attended at least one group event during the year. Many of the students reported that they would prefer more contact time, however overall satisfaction with the mentoring provision was high. During mentoring sessions, three-quarters of mentees discussed stress and coping, two-thirds discussed relationships (family and dating/romantic relationships), social skills, and employment/careers, and just over half discussed academic issues and emotional concerns. These topics corresponded with the student-identified goals for mentoring, although this could be because the goals were retrospectively identified.

The mentoring literature more generally indicates that mentees' experience is likely impacted by their relationship with their mentor, and the quality and nature of mentor supervision (Young \& Perrewé, 2000). These factors can be promoted via mentor support and training (Rajuan, Tuchin, \& Zuckermann, 2011) and studies on befriending or mentoring students with ASD indicate that specific training on ASD is imperative (Hamilton, Stevens, \& Girdler, 2016; Mavropoulou \& Avramidis, 2012; Rajuan et al., 2011). Mentor training should also promote awareness of MHC, as the rate of psychiatric comorbidity is higher for individuals with high-functioning autism than for the general population (Mazzone, Ruta, \& Reale, 2012). Prevalence estimates vary, but around $70 \%$ of individuals with ASD may have concomitant MHC, particularly anxiety and depression (Mazefsky, Folstein, \& Lainhart, 2008; Simonoff et al., 2008; Skokauskas \& Gallagher, 2010; van Steensel, Bögels, \& de Bruin, 2013).

\section{Mental health conditions}

Mental health conditions (MHC) are disorders which affect mood, thinking and behaviour, for example anxiety and depressive disorders. The prevalence of MHC within the general population is high - the 2014 England adult psychiatric morbidity survey found that $17 \%$ of adults met the diagnostic criteria for a common mental disorder e.g. depression or anxiety (Stansfeld et al., 2016). However, in the 20142015 academic year only $1.7 \%$ of first year UK domiciled undergraduate students 
declared a clinically diagnosed MHC in the absence of a concomitant disability (such as a sensory impairment, neurodevelopmental disorder or physical disability; HESA, 2016). Whilst this percentage is small, MHC were declared by over 9,800 students, making this the $2^{\text {nd }}$ most commonly reported disability after specific learning differences (HESA, 2016).

MHC can have a negative impact on the university experience. For example, individuals with MHC tend to have lower educational attainment than their peers (Andrews \& Wilding, 2004; Breslau, Lane, Sampson, \& Kessler, 2008; Hysenbegasi, Hass, \& Rowland, 2005; Van Ameringen, Mancini, \& Farvolden, 2003). This may be partially attributable to reduced capacity to focus attention and poorer engagement in class; MHC can reduce the available cognitive capacity (Castaneda, Tuulio-Henriksson, Marttunen, Suvisaari, \& Lönnqvist, 2008). Additionally, individuals with MHC may be more reluctant to engage in group work with their peers, and in general are more likely to have poorer peer relationships (Brumariu, Obsuth, \& Lyons-Ruth, 2013; Crawford \& Manassis, 2011).

Like students with ASD, students with MHC can be recommended mentoring by DSA Needs Assessors. However, there is a lack of research on the effectiveness of mentoring for students with clinical levels of MHC. A small number of evaluations of mentoring programmes for students on medical programmes (which are considered to be especially demanding and stressful) are positive. More specifically those students who receive mentoring have less anxiety, improved self-confidence, greater time management, perceive the learning environment as less stressful, attain higher grades and have greater interaction with their peers, than students who do not receive mentoring (Harmer, Huffman, \& Johnson, 2005; Kim, Oliveri, Riingen, Taylor, \& Rankin, 2013; Sprengel \& Job, 2004).

\section{Mentors' and mentees' perspectives}

It is important to understand not only whether mentoring provision for students with ASD and/or MHC is effective or not, but also why. Yet the small number of evaluations tend to focus upon outcomes and not experiences. Little is known about the student mentees' perspectives on this form of support, and what they perceive to be essential components of mentoring support. To date there is limited qualitative investigation of the experiences of student mentees with ASD and/or MHC.

Additionally the experience of the mentors is likely to affect the successfulness of mentoring provision. A study into the Big Brothers Big Sisters mentoring programme for school pupils found that aspects of the mentoring relationship, such as mentors' perceptions of emotional closeness, were associated with increased benefits for mentees (DuBois \& 
Neville, 1997). Exploring the impact of mentoring on the personal development of mentors working with students with ASD has been identified as an important avenue for future research (Hamilton et al., 2016).

Whilst mentoring is designed to promote the academic/employability and psychosocial wellbeing of the mentees, research on peer mentoring indicates that mentors may also benefit. Benefits reported include the development of interpersonal and communication skills (Dearden, 1998; James, Smith, \& Radford, 2014; Thompson \& Smith, 2011), enhanced employability-related skills (Chester, Burton, Xenos, \& Elgar, 2013; James, 2014), and enhanced self-esteem and self-confidence (Mentoring and Befriending Foundation, 2011). Furthermore, mentors can find reflecting on their experiences beneficial (Hill \& Reddy, 2007) and experience a sense of achievement and a sense of fulfilment from helping others (Hill \& Reddy, 2007; James et al., 2014).

However, there is a lack of research exploring both the experiences of mentors working with university students with conditions such as ASD and/or MHC, and the perceptions of the students themselves. Extrapolation of the findings discussed above suggests that the benefits for mentors working with ASD and/or MHC populations may be especially evident, but the nature of these students' disabilities could make developing a successful mentoring relationship challenging and attenuate the benefits for both mentors and mentees.

\section{The current study}

Little is known about specialist mentoring provision for students with ASD and/or MHC, nor the optimal ways of delivering this service. The current study therefore examined mentees' expectations of mentoring, as well as their experience. In addition to providing descriptive information about the benefits of receiving mentoring, we also sought to understand why mentoring could be beneficial. We achieved this through a mixed methods design involving both questionnaires and interviews. Uniquely, we also considered the mentors' expectations and experience, as this will likely impact the motivation of the mentors and the quality of the mentoring provided. This information can be used to guide the development and refinement of optimal specialist mentoring services, thereby enhancing the mentee (and mentor) experience. 


\section{Method}

\section{Design}

A mixed-method evaluation was conducted of a university mentoring service. Study measures were piloted in the Summer term of 2015, and at the start of the next academic year (2015-16) all undergraduate students designated mentoring by DSA Needs Assessors for social communication difficulties $(n=32)$ or mental health problems $(n=21)$, and their specialist mentors $(n=12)$, were invited to participate in the main evaluation phase. Data were collected in the Autumn 2015, Spring 2016, and Summer 2016 terms using on-line questionnaires, run via Qualtrics (Qualtrics, Provo, UT), with additional interviews in the Summer term. The study was in accordance with the British Psychological Society guidelines for ethical practice, and ethical approval was granted by the XXX university Psychology department.

\section{Piloting}

Three mentees with ASD (2 male), two mentees with MHC (1 male) and five specialist mentors (3 male) completed a questionnaire regarding their mentoring experience, and participated in a semi-structured interview (mentees) or focus group (mentors). The content was developed based on previous studies exploring mentoring (Ames et al., 2015; James et al., 2014; Smith \& Watson, 2004). Data analysis identified additional areas of importance, e.g. the mentee-mentor relationship, and the questionnaires and interview scripts were revised accordingly. 


\section{Mentees}

\section{Expectations}

In the Autumn term eight mentees with $\mathrm{ASD}$ (mean age $=18.98, \mathrm{SD}=.59 ; 6$ male) and 7 mentees with $\mathrm{MHC}$ (mean age $=22.06, \mathrm{SD}=3.27 ; 1$ male) completed a questionnaire regarding their expectations of the mentoring programme. At the time of questionnaire completion, mentees with ASD had received on average 8 mentoring sessions ( $\mathrm{SD}=3.58$ ), whilst mentees with MHC had received $6(\mathrm{SD}=6.00), t(14)=1.39, p=.187$.

Mentees rated the extent to which they agreed with statements beginning "I hope the mentoring scheme will help me with..." using a 5-point Likert scale (1 'Strongly Disagree' to 5 'Strongly Agree'). There were 33 questionnaire items, across three domains: 1) academic skills and university life, 2) social relationships and skills, and 3) well-being (see Figure 1 for item details).

\section{Experiences}

In the Spring term, 3 of the mentees with ASD who completed the expectations questionnaire completed a questionnaire on their mentoring experiences, as did 4 other mentees with ASD (total $n=7,4$ male; mean age $=19.74, \mathrm{SD}=.72$ ). In addition 5 of the mentees with MHC who completed the expectations questionnaire also completed the experiences questionnaire, as did 2 other mentees with $\mathrm{MHC}$ (total $\mathrm{n}=7,1$ male; mean age $=$ 20.77, $\mathrm{SD}=3.07)$. Mentees with ASD had received on average 18 sessions $(\mathrm{SD}=15.83)$, whilst mentees with MHC had received on average 11 sessions $(\mathrm{SD}=4.65), t(12)=1.01, p=$ .347 .

In the Summer term, 6 mentees with ASD (4 male; mean age $=20.19, \mathrm{SD}=.77$ ) completed the second experiences questionnaire. They had all completed at least one of the other questionnaires. Eight mentees with MHC (1 male; mean age $=21.69, \mathrm{SD}=3.34)$ also completed the second experiences questionnaire. Seven had completed at least one of the other questionnaires. Mentees with ASD had received on average 33 sessions ( $\mathrm{SD}=3.51$ ), whilst mentees with MHC had received on average 21 sessions $(\mathrm{SD}=7.74), t(12)=1.25, p=$ .237 .

The 'experience' questionnaires contained the same items as the expectations questionnaire, but with the sentence stem "This academic year the mentoring scheme has helped we with...". In both terms six additional questions on the mentee-mentor relationship were included and mentees were asked whether they felt the scheme had been a positive 
experience. In the Summer term five questions about the exam period and two questions about preparation for the following academic year were further added. All item details, and Cronbach's alpha values for each domain in the Summer term, are shown in Figure 1.

In the Summer term, five mentees (3 with ASD [2 male] and 2 with MHC [0 male]; mean age $=21.09, \mathrm{SD}=3.76$ ) participated in interviews about their mentoring experience. The interviews covered: 1) reasons for engaging in the program, 2) what the program involved (e.g. type of mentoring, frequency of sessions), 3) satisfaction with both the program content and the logistics, with emphasis on both the strengths and areas for improvement, and 4) potential adaptations in light of DSA changes e.g. mentor qualification requirements.

\section{[INSERT FIGURE 1 HERE]}

\section{Mentors}

All mentors were specialist mentors who were employed by the university (rather than peer mentors). In line with the requirements of Student Finance England, the mentors had relevant previous experience and received specialist training organised by the Disability and Dyslexia Service. This included information about different disorders, suggestions for mentoring session content and discussion of example scenarios.

\section{Experiences}

In the Autumn term, five mentors ( 3 male) completed a questionnaire on their expectations for the mentoring scheme that year. They ranged in age from 38-63 $(\mathrm{Mean}=$ 47.04, $\mathrm{SD}=10.83$ ). Two had just commenced the mentoring role and three were returning mentors. They mentored between 3-14 mentees. The mentors rated the extent to which they agreed with statements beginning "I feel that I will..." using a 5-point Likert scale (1 'Strongly Disagree' to 5 'Strongly Agree'). There were 24 questionnaire items, across three domains: 1) the university community, 2) their relationship with their mentees, and 3) their mentoring role (see Figure 2 for item details).

\section{Expectations}

In the Spring and Summer terms four of the mentors (2 male) who completed the expectations questionnaire also completed a questionnaire on their experiences of the mentoring scheme so far that year. In addition, in the Spring term one female mentor (aged 21 with 3 mentees) on a short term temporary contract completed the experience questionnaire, and in the Summer term, one long term female mentor (aged 53, with 2 mentees) who had not completed the previous questionnaires participated. 
The 'experiences' questionnaire contained the same items as the expectations questionnaire, but with the sentence stem amended to "This academic year I have...". Additionally, like mentees, mentors were asked to rate their overall experience, and in the summer term five questions about the exam period and two questions about preparation for the following academic year were added. All item details, and Cronbach's alpha values for each domain in the Summer term, are shown in Figure 2. The low alpha coefficients evident for two of the scales may be attributed to the small number of scale items.

In the Summer term, four mentors ( 3 male; mean age $=44.20 \mathrm{SD}=7.73$ ) participated in interviews. The interviews covered: 1) reasons with engaging in the program, 2) what the program involved, 3) satisfaction with both the program content and the logistics, with emphasis on both the strengths and areas for improvement, 4) the impact of the scheme on them personally and in respects to their perceptions of the university, and 5) perception of DSA changes.

\section{[INSERT FIGURE 2 HERE]}

\section{Data analysis}

Group differences between mentees with ASD and MHC, in terms of their expectations and experiences, were analysed using t-tests, and a multiple regression analysis was used to investigate which variables predicted mentees' overall satisfaction in the Summer term. Due to the small sample size, descriptive data only is reported for mentors' expectations and experiences. The interviews with mentors and mentees were transcribed, and analysed using thematic analysis (as specified by Braun \& Clarke, 2006) to identify central aspects in the mentoring process. Coding was primarily conducted by XXX, with validation checks performed by XXX to ensure that findings reflected the participants' experiences. Thematic analysis was initially conducted separately by participant group (mentees with ASD; mentees with MHC; mentors), but as the same themes emerged across groups findings were combined into a single thematic map.

\section{Results}

\section{Mentee expectations}

Mentees hoped that mentoring would help them with their academic skills and university life, social relationships and skills, and their well-being, see Table 1. The composite scores of these three domains were compared for the ASD and MHC groups and 
there were no group differences (all $t<.710$, all $p>.485$ ). There were also no group differences at the item level (all $t \leq 1.11$, all $p \geq .280$ ).

\section{[INSERT TABLE 1 HERE]}

\section{Mentee experiences}

\section{Overall satisfaction}

In the Spring term, overall satisfaction with the mentoring experience was high, especially for the ASD group, see Table 1. All of the mentees with ASD responded 'Strongly agree' or 'Agree' to this question. Four of the seven (57\%) mentees with MHC were also satisfied with the overall experience and the average score was slightly lower than that of the ASD group, $t(12)=1.84, p=.091$, Cohen's $d=.99$. However, by the Summer term six of the eight $(75 \%)$ mentees with MHC were satisfied with the overall experience, and there were no group differences in the satisfaction of the mentees with ASD and MHC, $t(12)=1.09, p=$ .298 .

\section{Academic attainment and university life}

Both mentees with ASD and those with MHC felt that mentoring had helped them with academic skills and university life, see Table 1. In the Spring term, this was especially the case for the ASD group, whose average score across items was significantly higher than that of the MHC group, $t(12)=2.45, p=.031$, Cohen's $d=1.34$. The ASD group found mentoring especially helpful for increasing confidence in their studies (ASD: $M=4.43, S D=$ .54 ; MHC: $\mathrm{M}=3.57, \mathrm{SD}=.79, t(12)=2.38, p=.035$, Cohen's $d=1.27)$. By the Summer term the divide had decreased due to the increased satisfaction of the mentees with MHC, $t(12)=1.85, p=.089$, Cohen's $d=.12$. However, the ASD group were more likely than their peers with $\mathrm{MHC}$ to report that mentoring was beneficial for developing time management skills (ASD: $\mathrm{M}=4.17, \mathrm{SD}=.41 ; \mathrm{MHC}: \mathrm{M}=3.50, \mathrm{SD}=.54, t(12)=2.65, p=.021)$. Additionally, mentoring was more beneficial for helping students with ASD feel comfortable in the university environment (ASD: $\mathrm{M}=4.83, \mathrm{SD}=.54$; $\mathrm{MHC}: \mathrm{M}=4.25, \mathrm{SD}=.46, t(12)=$ $2.45 p=.031$, Cohen's $d=1.16$ ), which there was a non-significant trend for in the Spring term.

\section{Social relationships and skills}

Mentees with ASD also felt that mentoring during the first term had helped them with their social relationships and skills, whilst mentees with MHC were more neutral regarding the support received, see Table 1. Concordantly, there was a trend of the ASD group to find 
mentoring especially beneficial for maintaining and developing social relationships and skills, $t(12)=1.87, p=.086$, Cohen's $d=1.04$, which reflected the trends for mentees with ASD to find mentoring particularly helpful in terms of meeting new people (ASD: $M=4.29, \mathrm{SD}=$ .76 ; $\mathrm{MHC}: \mathrm{M}=3.57, \mathrm{SD}=.54, t(12)=2.04 p=.064)$ and feeling that they have a peer group at university where they belong and feel understood (ASD: $\mathrm{M}=4.14, \mathrm{SD}=.90 ; \mathrm{MHC}: \mathrm{M}=$ $3.14, \mathrm{SD}=.90 t(12)=2.08 p=.060)$. However, by the Summer term the divide had decreased, again due to the increased satisfaction of the mentees with MHC, $t(12)=1.37, p=$ .197.

\section{Well-being}

In addition, mentees with ASD reported that mentoring had helped them with their well-being, whilst mentees with MHC did not report that mentoring was as beneficial for their well-being, $t(12)=2.33, p=.038$ Cohen's $d=1.24$, see Table 1 . The ASD group found mentoring especially beneficial for helping with coping skills (ASD: $\mathrm{M}=4.29, \mathrm{SD}=.76$; MHC: $\mathrm{M}=3.57, \mathrm{SD}=.54, t(12)=2.72 p=.019$, Cohen's $d=1.09$ ) and for feeling positive about the future in general (ASD: $\mathrm{M}=4.29, \mathrm{SD}=.76 ; \mathrm{MHC}: \mathrm{M}=3.57, \mathrm{SD}=.54, t(12)=$ $2.94 p=.012$, Cohen's $d=1.09$ ). In the Summer term, mentees with ASD were still finding support for well-being more helpful than their peers with MHC, $t(12)=2.36, p=.036$, Cohen's $d=1.26$. In particular mentoring was especially beneficial for the ASD group relative to MHC group in terms of developing problem solving skills (ASD: $\mathrm{M}=4.67, \mathrm{SD}=$ $.52 ; \mathrm{MHC}: \mathrm{M}=4.00, \mathrm{SD}=.54, t(12)=2.34 p=.038)$ and dealing with unexpected events $(\mathrm{ASD}: \mathrm{M}=4.50, \mathrm{SD}=.55 ; \mathrm{MHC}: \mathrm{M}=3.75, \mathrm{SD}=.71, t(12)=2.15 p=.053$, Cohen's $d$ $=1.18)$.

\section{Mentor relationship}

In the Spring term, mentees with ASD indicated that they were satisfied with the mentee-mentor relationship, whilst mentees with MHC were more neutral, $t(12)=3.03, p=$ .010 , Cohen's $d=2.38$, see Table 1. Group differences were evident across all individual items (all $t>2.40, p<.035$ ) bar two, namely ease of feeling comfortable talking to mentor $t(12)=1.90, p=.081$, and ease of contacting mentor, $t(12)=1.31, p=.216$. However, by the Summer term no differences were evident at the group level, $t(12)=1.34, p=.215$, nor the item level. This may be partially attributable to the speed at which the DDS addressed mentees concerns.

\section{Exam support}


In the Summer term, mentees also received support relating to their exams and there was again a trend for mentees with ASD to be more satisfied with this than their peers with MHC, $t(12)=1.99, p=.071$, Cohen's $d=1.08$, see Table 1 , especially in terms of helping with exam stress, $t(12)=2.23, p=.046$, Cohen's $d=1.18$. Likewise, mentees with ASD reported greater support with preparation for the next academic year with regards to course selection, $t(11)=1.91, p=.082$, Cohen's $d=1.24$. However, support for accommodation arrangements was high for both groups, $t(10)=1.14, p=.203$.

To determine predictors of overall satisfaction reported in the Summer term simultaneous multiple regression analysis was conducted. Due to the small sample size, caution was required in terms of the number of predictor variables which could be entered into the model. Accordingly, a 'support areas' composite score was created by averaging the academic skills and university life, social relationships and skills and well-being composite scores which were all correlated $(r>525, p \leq .05)$. Four predictor variables were entered into the model: number of mentoring sessions, group (ASD vs MHC), support areas composite, and mentoring relationship. Table 2 shows zero-order and semi-partial correlations between overall satisfaction and each predictor variables. The total model was significant, $F(4$, 13) $=4.08, p=.037$, and explained $64.43 \%$ of the variance. However, mentoring relationship was the only significant predictor, $\beta=1.01, t=3.41, p=.008$.

\section{[INSERT TABLE 2 HERE]}

\section{Mentor expectations}

When asked at the start of the academic year about their expectations for the mentoring role, mentors reported feeling that they had personal skills relevant to the mentoring role, that the mentor-mentee relationship would be strong, that they would cope well with the mentoring role, and that they would be comfortable in the university environment, see Table 3.

\section{Mentor experiences}

Throughout the academic year mentors reported that they had developed their personal skills, were satisfied with the university experience, had a strong relationship with their mentee and were positive about the mentoring role, see Table 3. Concordantly, they were highly satisfied with the overall experience, both in the Spring and Summer terms. In the Summer term mentors also felt that they had provided their mentees with support relating to exams. Three mentors indicated that they had helped prepare them for the next academic year in terms of accommodation arrangements and two had discussed course selection. 


\section{[INSERT TABLE 3 HERE]}

\section{Thematic analysis}

The thematic map in Figure 3 depicts the central theme (Tailored Partnership), main themes and sub-themes which emerged from the qualitative data. A description of each main theme is provided below with illustrative quotes, where mentors (M) and student mentees (S) are identified by unique ID numbers. Sex, condition and other personal information are not signified in order to protect participants' identities given the small numbers involved.

\section{[INSERT FIGURE 3 HERE]}

\section{Central theme: Tailored Partnership}

Mentoring was effective when the mentor-mentee relationship was tailored to the student's needs; mentors needed to understand that needs vary across individuals, including amongst those who share conditions, and over time.

"It's completely tailored to you and your needs" - S22

"It varies a lot and I think it has to be really tailored to an individual" - M1

Mentors acted as bridges, helping students to find ways to tailor the university environment for their needs and to learn strategies to work well within it. Mentees valued having a personal relationship with their mentor, describing it as a friend-like partnership where the nature of the support was negotiated. This support appeared to be successful through empowerment of the mentees.

\section{Bridges}

Mentors acted as bridges across transition points and gaps between the mentee's needs and standard university provision. They supported new students in making the university transition to being in higher education and potentially living at university. Mentoring helped mentees to integrate into the university community, often going beyond academic and emotional support into social and extracurricular domains.

"I think it would have been a lot more challenging, possibly to the point where I might have actually left. Yeah there were times when I was seriously considering just packing it all in but yeah, like I said, [mentor] made it feel like it was a bit more manageable."- S22

Mentors could also bridge the transition from parental support to independence, through offering support that might previously have been given by parents and by guiding 
students. Where desired by a mentee they could also work with students' families, to communicate about their needs and development at university.

"Just that it would be someone that I could touch base with and like go through any problems. Help settle while I'm away from my family." - S20

Even with mentoring support, adjustments to standard university provision might be required as a result of a mentee's condition. Mentees reported challenges in liaising with academic departments but mentors could act as advocates, bridging any communication difficulties between the mentee and wider university services.

"I think it can be really helpful just having a point of contact within the university, someone who can advocate for you, someone who can keep an eye on your study skills" - S12

The close personal relationship means that mentors might be the first person to notice when a mentee was having problems, and flag up the need for further support.

"My job is to meet them and ring the bell when I sense that somebody else needs to be called" - M4

\section{Personal Relationship}

Mentees indicated that the personal relationship with their mentor was facilitated by finding shared experiences, such as holding personal or academic interests in common. The relationship formed was thus unique and linked to both mentors' and mentees' social identities.

Mentees strongly appreciated it when they perceived their mentor to be taking genuine interest, for example by remembering details from a previous meeting. Mentees valued being seen as whole individuals by their mentors, rather than being defined by their condition.

"I guess it's the personal relationship. Again, how [mentor] generally shows interest, you know, in the things I like and the things I want to talk about." - S6

Mentees appreciated that the university left mentor-mentee pairs to negotiate the mentoring relationship rather than stipulating what it should involve. Students perceived this to enable them to have an effective, personalised relationship which was adaptive to their needs. 
"I sometimes forget it's run by them [the university disability service] because there isn't much input and I think sometimes that's a good thing. You're able to just step back and do it." - S20

The nature of mentees' conditions could mean that they were unable to make meetings or could require support with unexpected problems. The level of flexibility required could be challenging for mentors, but was highly valued by their mentees.

The relationship was often perceived by mentees as a friendship; they felt that rather than acting as an authority figure, their mentor treated them as being on the same level.

"In terms of initiating meetings and stuff it was very 50-50... It was like, you know, talking to a friend. Like if I wanted to see them I could send them a message and ask them if they wanted to meet..." - S5

However, mentors were more aware of the power dynamics inherent in the relationship, given that mentors were employed to provide a service for potentially vulnerable students.

"There's a disparity in the relationship from the beginning. We're not equals. And we're not equals because of the job that I do... I think I'm friendly with them, there's a difference between that and being friends." - M2

Some mentees had changed mentors as a result of feeling that their first mentor was not a good match for them; these mentees experienced a sense of powerlessness in the first mentoring relationship.

"I think something's gone really wrong here and because of the nature of my [condition] problems and my issue with authority figures I didn't feel able to, kind of, properly challenge it." - S12

In these instances the individualised nature of the mentoring relationship, with mentors having different approaches, had initially been problematic but facilitated a successful experience following a change in mentor.

\section{Empowerment}

Mentors can empower their mentees, and boost their confidence and self-esteem. Mentoring involved guiding not directing; mentors provided information and advice, tailored 
to students' individual needs and condition, but did not make students go about things in a certain way.

"I never felt like I was being patronised. There was no telling me what to do, just advice, helping and yeah it was good really." - S1

The mentoring scheme operated as both prevention and intervention. Mentees receive guidance with any difficulties which arise, but mentoring support may mean that fewer problems develop or that they are less serious. Mentees, both those with ASD and MHC, often spoke about the link between their mental wellbeing and their ability to do well academically.

“Otherwise I'd have probably been quite a bit more anxious and probably got a bit more stressed about deadlines and been a bit more unsure about some social situations, so yeah I think it definitely helped." - S2

Mentoring relationships provide safe spaces where students can raise questions or issues without fear of judgement. However, mentoring support may be challenging for the mentee; mentors may empower mentees to go out of their comfort zone to try to achieve social or academic goals.

"Like getting involved in things and meeting people. Doing stuff I wouldn't necessarily have pushed myself to do on my own." - S20

Mentors further empowered mentees by supporting them to develop positive identities. For a mentee with a MHC this took the form of being supported to look into mental health related careers. For students with ASD this could mean working with them as they claim an 'Aspie' identity or see the positives in their condition.

"We talk about the joys of the Aspie way of thinking about things; the focus on detail, the ability to organise thoughts, the ability to tell people to sod off so you can get on with your work... that this is who you are and you're quite awesome." - M3

The mentor quoted above summed up this aspect of the role as wanting mentees to find their "own awesomeness" (M3). 


\section{Discussion}

\section{Summary of findings}

Despite over $10 \%$ of students at UK universities declaring disabilities, there is little empirical evidence of the efficacy of specialist provision. The current evaluation of a mentoring scheme for university students with ASD and/or MHC therefore makes an important contribution by examining the extent to which mentoring impacted multiple domains and exploring the central aspects of the mentoring process, using a mixed methods approach. Mentees with ASD and those with MHC hoped for, and received, support with academic, social and emotional development, although subtle group difference emerged in satisfaction with the support. Overall satisfaction was predicted by the quality of the menteementor relationship and thematic analysis highlighted how important a personalised, tailored approach is, from both the mentees and mentors perspectives.

Mentees with ASD reported that they were satisfied with the support for academic skills and university life (including exam support), social relationships and skills, and wellbeing. Correspondingly, overall satisfaction was high, as was also the case for the mentees with ASD surveyed by Ames et al. (2015). In the spring term, mentees with MHC were less positive about their experience across all domains, however by the Summer term group differences were reduced. Examination of the survey in-text comments and the qualitative analysis indicated that this was driven by the mentor-mentee relationship, the importance of which has previously been highlighted (cf. Young \& Perrewé, 2000). Two mentees with MHC had a negative relationship with their original mentor, and both changed mentor. After developing a postive relationship with their new mentor their overall exerience of the scheme was also positive. Indeed, the quality of the mentee-mentor relationship in the summer term was the strongest predictor of mentees' overall satisfaction.

Mentors also reported high satisfaction with the mentoring relationships. This is important as mentor experiences have previously been shown to impact the quality of provision (Young \& Perrewé, 2000). In both the spring and summer terms, mentors were positive about the university community, their mentor-mentee relationship, the mentoring role and their overall experience. They also reported that as well as witnessing the benefits of mentoring for mentees, they personally benefited from the experience, for example in terms of skill development and a sense of satisfaction from helping others (cf. Hilly \& Reddy, 2007; James et al., 2014). 
This study went beyond examining whether mentoring was effective, and importantly explored why the mentoring process could be effective. Mentees valued the tailored partnership with their mentor, which involved a personal relationship. They described the relationship with their mentor as a friend-like partnership, although mentors showed increased awareness of the professional nature of their role. Mentors acted as bridges helping students to find ways to tailor the university environment for their needs and to learn strategies to work well within it. This supported the students' academic development, but was also beneficial in terms of social integration and emotional well-being. Successful support took the form of guidance rather than direction; this empowered the mentees, boosting their confidence and self-esteem. These social and emotional benefits in turn meant that mentees were more able to face academic challenges. Therefore mentoring contributed to 'prevention' of difficulties, and was not solely an 'intervention'.

\section{Limitations and future research}

This mixed-methods study adds to the limited literature on mentoring provision for students with disabilities. As the study was conducted at a single site the sample size is relatively small, but comparable with previous research (e.g. Ames et al., 2015). It will be important for future research to examine the experiences and support needs of larger groups of individuals, ideally from different universities. The potential for integrating evaluation measures into routine mentoring practice should also be explored to increase the likelihood of collecting impact data from all mentees and mentors across the academic year.

Comparisons of students with ASD, with and without MHC, and with different MHC were beyond the scope of the current study. Given the heterogeneity of these conditions such comparisons are important avenues for future research, although the high co-occurrence of disorders makes this challenging. Interestingly our quantitative analyses suggest subtle differences in the satisfaction of mentees with ASD and MHC, but the qualitative analyses indicate that what makes the mentoring process effective is the same across conditions.

\section{Practical implications}

Our findings indicate that mentoring is beneficial for the social and emotional development of students with ASD and MHC, as well as their retention at university and academic success. We therefore recommend that mentoring remains a key form of university support, whether funded by the DSA in the UK or universities themselves. Mentoring provision functions as prevention and intervention, meaning that it is an investment which is 
likely to alleviate demand on other university support services, such as medical centres and student welfare.

Given the benefits for individual students and wider university services, it is important that all students who would benefit from mentoring support are able to access it. Whilst less than 2\% of first year UK university students declare a MHC (HESA, 2016), the actual percentage of students with clinically significant symptoms may be much higher (e.g. Eisenberg, Gollust, Golberstein, \& Hefner, 2007). Clearly signposting the availability of mentoring and other support provision to applicants and existing students could encourage further students to register with university disability services.

There is currently little guidance on what the nature of specialist mentoring should be, beyond the recommended number of hours for each mentee. Mentees in our study valued being able to negotiate the nature of the mentoring relationship with their mentor, rather than the nature of support being prescribed by the university - although it is crucial that mentees have avenues to raise any problems with their mentoring partnership. However we recommend that mentors should be well connected with the university they work within, in order to help students navigate the new environment and to liaise with wider university services. Overall our study indicates that effective mentoring support is flexible; mentors adapt the support they provide to the needs of their individual mentees, working with them as whole individuals, recognising the positive aspects of their conditions, and empowering them to face challenges. 


\section{Compliance with Ethical Standards}

Conflict of Interest: The authors declare that they have no conflict of interest.

Ethical approval: All procedures performed in this study involving human participants were in accordance with the ethical standards of the institutional and/or national research committee and with the 1964 Helsinki declaration and its later amendments or comparable ethical standards.

Informed consent: Informed consent was obtained from all individual participants. 


\section{References}

AGCAS Disability Task Group. (2014). What Happens Next? A Report on the First Destinations of 2014 Disabled Graduates.

American Psychological Association. (2013). Diagnostic and Statistical Manual of Mental Disorders (DSM-V). Arlington, Va, USA: American Psychiatric Association.

Ames, M., McMorris, C., Alli, L., \& Bebko, J. (2015). Overview and evaluation of a mentorship program for university students with ASD. Focus on Autism and Other Developmental Disabilities. doi: 10.1177/1088357615583465

Andrews, B., \& Wilding, J. (2004). The relation of depression and anxiety to life-stress and achievement in students. British Journal of Psychology, 95(4), 509-521. doi: 10.1348/0007126042369802

Baird, G., Simonoff, E., Pickles, A., Chandler, S., Loucas, T., Meldrum, D., \& Charman, T. (2006). Prevalence of disorders of the autism spectrum in a population cohort of children in South Thames: the Special Needs and Autism Project (SNAP). The Lancet, 368(9531), 210-215. doi: 10.1016/s0140-6736(06)69041-7

Beardon, L., Martin, N., \& Woolsey, I. (2009). What do students with AS and HFA want at college or university? (In their own words). GAP, 10(2), 35-43.

Braun, V., \& Clarke, V. (2006). Using thematic analysis in psychology. Qualitative Research in Psychology, 3(2), 77-101. doi: 10.1191/1478088706qp063oa

Breslau, J., Lane, M., Sampson, N., \& Kessler, R. (2008). Mental disorders and subsequent educational attainment in a US national sample. Journal of Psychiatric Research, 42(9), 708-716. doi: 10.1016/j.jpsychires.2008.01.016

Brugha, T. S., McManus, S., Bankart, J., Scott, F., Purdon, S., Smith, J., . . Meltzer, H. (2011). Epidemiology of autism spectrum disorders in adults in the community in England. Archives of General Psychiatry, 68(5), 459-465. doi: 10.1001/archgenpsychiatry.2011.38

Brumariu, L., Obsuth, I., \& Lyons-Ruth, K. (2013). Quality of attachment relationships and peer relationship dysfunction among late adolescents with and without anxiety disorders. Journal of Anxiety Disorders, 27(1), 116-124. doi: 10.1016/j.janxdis.2012.09.002

Cai, R., \& Richdale, A. (2016). Educational experiences and needs of higher education students with Autism Spectrum Disorder. Journal of Autism and Developmental Disorders, 46(1), 31-41. doi: 10.1007/s10803-015-2535-1

Castaneda, A. E., Tuulio-Henriksson, A., Marttunen, M., Suvisaari, J., \& Lönnqvist, J. (2008). A review on cognitive impairments in depressive and anxiety disorders with a focus on young adults. Journal of Affective Disorders, 106(1-2), 1-27. doi: 10.1016/j.jad.2007.06.006

Centers for Disease Control and Prevention. (2009). Prevalence of Autism Spectrum Disorders. Morbidity and Mortality Weekly Report (Vol. 58).

Centers for Disease Control and Prevention. (2014). Prevelance of autism spectrum disorder among children aged 8 years - Autism and Developmental Disabilities Monitoring Network. Surveillance Summaries (Vol. 63, pp. 1-22).

Charman, T., Pickles, A., Simonoff, E., Chandler, S., Loucas, T., \& Baird, G. (2011). IQ in children with autism spectrum disorders: Data from the Special Needs and Autism Project (SNAP). Psychological Medicine: A Journal of Research in Psychiatry and the Allied Sciences, 41(3), 619-627. doi: 10.1017/s0033291710000991 
Chester, A., Burton, L. J., Xenos, S., \& Elgar, K. (2013). Peer mentoring: supporting successful transition for first year psychology undergraduate students. Australian Journal of Psychology, 65(30-37). doi: 10.1111/ajpy.12006

Crawford, A. M., \& Manassis, K. (2011). Anxiety, social skills, friendship quality, and peer victimization: An integrated model. Journal of Anxiety Disorders, 25(7), 924-931. doi: 10.1016/j.janxdis.2011.05.005

Dearden, J. . (1998). Cross-age peer mentoring in action. Educational Psychology in Practice, 13, 250 257. doi: $10.1080 / 0266736980130406$

Dennis, M., Lazenby, A., \& Lockyer, L. (2001). Inferential language in high-function children with autism. Journal of Autism and Developmental Disorders, 31(1), 47-54. doi: 10.1023/a:1005661613288

Department for Business Innovation \& Skills. (2015a). Consultation on targeting funding for disabled students in Higher Education from 2016/17 onwards.

Department for Business Innovation \& Skills. (2015b). Government response: Consultation on targeting funding for disabled students in Higher Education from 2016/17 onwards.

DuBois, D. L., \& Neville, H. A. (1997). Youth mentoring: Investigation of relationship characteristics and perceived benefits. Journal of Community Psychology, 25(3), 227-223. doi: $10.1002 /(\mathrm{SICI}) 1520-6629$

Eisenberg, D., Gollust, S., Golberstein, E., \& Hefner, J. (2007). Prevalence and correlates of depression, anxiety, and suicidality among university students. American Journal of Orthopsychiatry, 77(4), 534-542. doi: 10.1037/0002-9432.77.4.534

Elsabbagh, M., Divan, G., Koh, Y., Kim, Y., Kauchali, S., Marcín, C., . . Fombonne, E. (2012). Global prevalence of autism and other pervasive developmental disorders. Autism Research, 5(3), 160-179. doi: 10.1002/aur.239

Equality Change Unit. (2014). Equality in higher education: statistical report 2014. Part 2: students.

Fombonne, E., \& Chakrabarti, S. (2001). No evidence for a new variant of measles-mumps-rubellainduced Autism. Pediatrics, 108(4), e58. doi: 10.1542/peds.108.4.e58

Gelbar, N., Smith, I., \& Reichow, B. (2014). Systematic review of articles describing experience and supports of individuals with Autism enrolled in college and university programs. Journal of Autism and Developmental Disorders, 44(10), 2593-2601. doi: 10.1007/s10803-014-2135-5

Hamilton, J., Stevens, G., \& Girdler, S. (2016). Becoming a mentor: The impact of training and the experience of mentoring university students on the Autism Spectrum. PLOS ONE, 11(4), e0153204. doi: 10.1371/journal.pone.0153204

Harmer, B., Huffman, J., \& Johnson, B. (2005). Clinical peer mentoring: partnering BSN seniors and sophomores on a dedicated education unit. Nurse Educator, 36(5), 197-202. doi: 10.1097/NNE.0b013e3182297d17

Higher Education Statistics Agency. (2016). Students in higher education institutions: Students, qualifiers and staff data tables. Retrieved 19th July 2016, 2016, from www.hesa.ac.uk/index.php/content/view/1973/239/

Hill, R., \& Reddy, P. (2007). Undergraduate peer mentoring: An investigation into processes, activities and outcomes. Psychology Learning \& Teaching, 6(2), 98-103. doi: 10.2304/plat.2007.6.2.98

Hysenbegasi, A., Hass, S., \& Rowland, C. (2005). The impact of depression on the academic productivity of university students. The Journal of Mental Health Policy and Economics, 8 , 145-151. doi: 1099-176X 
James, A. I. (2014). Cross-age mentoring to support A-level pupils' transition into Higher Education and undergraduate students' employability. Psychology Teaching Review: Special Issue: Pedagogical Action Research, 20(2).

James, A. I., Smith, P. K., \& Radford, L. (2014). Becoming grown-ups: a qualitative study of the experiences of peer mentors. Pastoral Care in Education, 32(2), 104-115. doi: 10.1080/02643944.2014.893008

Kim, S., Oliveri, D., Riingen, M., Taylor, B., \& Rankin, L. (2013). Randomized controlled trial of graduate-to-undergraduate student mentoring program. Journal of Professional Nursing, 29(6), e43-e49. doi: 10.1016/j.profnurs.2013.04.003

Martin, I., \& McDonald, S. (2004). An exploration of non-literal language problems in individuals with Asperger syndrome. Journal of Autism and Developmental Disorders, 34(3), 311-312. doi: 10.1023/B:JADD.0000029553.52889.15

Mavropoulou, S., \& Avramidis, E. (2012). Befrienders to persons in the autistic spectrum in Greece: what support do they offer and what challenges they face? European Journal of Special Needs Education, 27(3), 337-353. doi: 10.1080/08856257.2012.691230

Mazefsky, C., Folstein, S., \& Lainhart, J. (2008). Overrepresentation of mood and anxiety disorders in adults with autism and their first-degree relatives: what does it mean? Autism Research, 1(3), 193-197. doi: 10.1002/aur.23

Mazzone, Luigi, Ruta, Liliana, \& Reale, Laura. (2012). Psychiatric comorbidities in asperger syndrome and high functioning autism: diagnostic challenges. Annals of General Psychiatry, 11, 16-16. doi: 10.1186/1744-859X-11-16

Mentoring and Befriending Foundation. (2011). National peer mentoring anti-bullying pilot 2008-10: A report setting out the main findings from the national peer mentoring anti-bullying pilot 2008-10.

Rajuan, M., Tuchin, I., \& Zuckermann, T. (2011). Mentoring the mentors: First-order descriptions of experience-in-context. The New Educator, 7(2), 172-190. doi: 10.1080/1547688X.2011.574592

Simonoff, E., Pickles, A., Charman, T., Chandler, S., Loucas, T., \& Baird, G. (2008). Psychiatric disorders in children with Autism Spectrum Disorders: Prevalence, comorbidity, and associated factors in a population-derived sample. Journal of the American Academy of Child \& Adolescent Psychiatry, 47(8), 921-929. doi: 10.1097/CHI.0b013e318179964f

Skokauskas, N., \& Gallagher, L. (2010). Psychosis, affective disorders and anxiety in Autistic Spectrum Disorder: Prevalence and nosological considerations. Psychopathology, 43(1), 8-16. doi: 10.1159/000255958

Smith, P. K., \& Watson, D. (2004). Evaluation of the CHIPS (ChildLine in Partnership with Schools) programme. Research report RR570. Nottingham, UK: Department for Education and Skills.

Sprengel, A., \& Job, L. (2004). Reducing student anxiety by using clinical peer mentoring with beginning nursing students Nurse Educator, 29(4), 246-250.

Stansfeld, S., C., Clark., Bebbington, P., King, M., Jenkins, R., \& Hinchliffe, S. (2016). Common mental disorders: Adult Psychiatric Morbidity Survey 2014.

Thompson, F., \& Smith, P. K. (2011). The use and effectiveness of anti-bullying strategies in schools. Research Report DFE-RR098. London, UK: Department for Education.

Van Ameringen, M., Mancini, C., \& Farvolden, P. (2003). The impact of anxiety disorders on educational achievement. Journal of Anxiety Disorders, 17(5), 561-571. doi: 10.1016/S08876185(02)00228-1 
van Bergeijk, E., Klin, A., \& Volkmar, F. (2008). Supporting more able students on the Autism Spectrum: College and beyond. Journal of Autism and Developmental Disorders, 38(7), 13591370. doi: $10.1007 /$ s10803-007-0524-8

Van Hees, V., Moyson, T., \& Roeyers, H. (2015). Higher education experiences of students with Autism Spectrum Disorder: Challenges, benefits and support needs. Journal of Autism and Developmental Disorders, 45(6), 1673-1688. doi: 10.1007/s10803-014-2324-2

van Steensel, F., Bögels, S., \& de Bruin, E. (2013). Psychiatric comorbidity in children with Autism Spectrum Disorders: A comparison with children with ADHD. Journal of Child and Family Studies, 22(3), 368-376. doi: 10.1007/s10826-012-9587-z

White, S., Elias, R., Salinas, C.., Capriola, N., Conner, C., Asselin, S., . . Getzel, E. (2016). Students with autism spectrum disorder in college: Results from a preliminary mixed methods needs analysis. Research in Developmental Disabilities, 56, 29-40. doi: 10.1016/j.ridd.2016.05.010

White, S., Ollendick, T., \& Bray, B. (2011). College students on the autism spectrum: Prevalence and associated problems. Autism, 11(6), 683-701. doi: 10.1177/1362361310393363

Wu, C., Tseng, L., An, C., Chen, H., Chan, Y., Shih, C., \& Zhuo, S. (2014). Do individuals with autism lack a sense of humor? A study of humor comprehension, appreciation, and styles among high school students with autism. Research in Autism Spectrum Disorders, 8(10), 1386-1393. doi: 10.1016/j.rasd.2014.07.006

Young, A., \& Perrewé, P. (2000). The exchange relationship between mentors and protégés: The development of a framework. Human Resource Management Review, 10(2), 177-209. doi: 10.1016/S1053-4822(99)00045-5 
SPECIALIST MENTORING FOR ASD Page | 26

Table 1. Mentees' expectations and experiences

\begin{tabular}{|c|c|c|c|c|c|c|}
\hline \multirow[t]{2}{*}{ Domains } & \multicolumn{2}{|c|}{$\begin{array}{l}\text { Expectations } \\
\text { Autumn term }\end{array}$} & \multicolumn{2}{|c|}{$\begin{array}{l}\text { Experience } \\
\text { Spring term }\end{array}$} & \multicolumn{2}{|c|}{$\begin{array}{c}\text { Experience } \\
\text { Summer term }\end{array}$} \\
\hline & $\begin{array}{c}\text { ASD } \\
\text { Mean (SD) }\end{array}$ & $\begin{array}{c}\text { MHC } \\
\text { Mean (SD) }\end{array}$ & $\begin{array}{c}\text { ASD } \\
\text { Mean (SD) }\end{array}$ & $\begin{array}{c}\text { MHC } \\
\text { Mean (SD) }\end{array}$ & $\begin{array}{c}\text { ASD } \\
\text { Mean (SD) }\end{array}$ & $\begin{array}{c}\text { MHC } \\
\text { Mean (SD) }\end{array}$ \\
\hline $\begin{array}{l}\text { Academic skills and } \\
\text { university life composite }\end{array}$ & $\begin{array}{l}4.24 \\
(.44)\end{array}$ & $\begin{array}{l}4.40 \\
(.45)\end{array}$ & $\begin{array}{l}4.13 \\
(.46)\end{array}$ & $\begin{array}{l}3.61 \\
(.33)\end{array}$ & $\begin{array}{l}4.23 \\
(.28)\end{array}$ & $\begin{array}{l}3.91 \\
(.34)\end{array}$ \\
\hline $\begin{array}{l}\text { Social relationships and } \\
\text { skills composite }\end{array}$ & $\begin{array}{l}4.27 \\
(.65)\end{array}$ & $\begin{array}{l}4.11 \\
(.56)\end{array}$ & $\begin{array}{l}4.07 \\
(.64)\end{array}$ & $\begin{array}{l}3.55 \\
(.35)\end{array}$ & $\begin{array}{l}4.25 \\
(.43)\end{array}$ & $\begin{array}{l}3.94 \\
(.42)\end{array}$ \\
\hline Well-being composite & $\begin{array}{l}4.40 \\
(.39)\end{array}$ & $\begin{array}{l}4.37 \\
(.47)\end{array}$ & $\begin{array}{l}4.23 \\
(.73)\end{array}$ & $\begin{array}{l}3.40 \\
(.67)\end{array}$ & $\begin{array}{l}4.53 \\
(.52)\end{array}$ & $\begin{array}{l}3.90 \\
(.48)\end{array}$ \\
\hline $\begin{array}{l}\text { Mentee-mentor } \\
\text { relationship composite }\end{array}$ & - & - & $\begin{array}{l}4.76 \\
(.37)\end{array}$ & $\begin{array}{l}3.83 \\
(.72)\end{array}$ & $\begin{array}{l}4.79 \\
(.28)\end{array}$ & $\begin{array}{l}4.38 \\
(.83)\end{array}$ \\
\hline Exam support composite & - & - & - & - & $\begin{array}{l}4.20 \\
(.52)\end{array}$ & $\begin{array}{l}3.60 \\
(.59)\end{array}$ \\
\hline Overall satisfaction & - & - & $\begin{array}{l}4.57 \\
(.54)\end{array}$ & $\begin{array}{c}3.71 \\
(1.11)\end{array}$ & $\begin{array}{l}4.66 \\
(.52)\end{array}$ & $\begin{array}{l}4.13 \\
(1.13)\end{array}$ \\
\hline
\end{tabular}


SPECIALIST MENTORING FOR ASD Page | 27

Table 2. Regression analysis predicting mentees' overall satisfaction in the summer term

\begin{tabular}{l|ccccc}
\hline Predictors & $\beta$ & $t$ & $p$ & $\begin{array}{c}\text { Zero-order } \\
\text { correlation }\end{array}$ & $\begin{array}{c}\text { Semi-partial } \\
\text { correlation }\end{array}$ \\
\hline Number of mentoring sessions & -.01 & -.18 & .433 & -.03 & -.26 \\
Group (ASD vs MHC) & -.24 & -.13 & .622 &.-30 & -.17 \\
Support areas & -.11 & -.18 & .862 & .41 & -.06 \\
Mentee-mentor relationship & 1.01 & 3.41 & .008 & .78 & .75 \\
\hline
\end{tabular}


Table 3. Mentors' expectations and experiences

\begin{tabular}{lccc}
\hline Domains & $\begin{array}{c}\text { Expectations } \\
\text { Autumn term } \\
\text { Mean (SD) }\end{array}$ & $\begin{array}{c}\text { Experience } \\
\text { Spring term } \\
\text { Mean (SD) }\end{array}$ & $\begin{array}{c}\text { Experience } \\
\text { Summer term } \\
\text { Mean (SD) }\end{array}$ \\
\hline Overall experience & - & 4.60 & 4.60 \\
Personal skills composite & 4.20 & $(.55)$ & $(.55)$ \\
& $(.30)$ & 4.20 & 4.08 \\
University community & 3.85 & $(.37)$ & $(.34)$ \\
composite & $(.45)$ & 3.80 & 4.33 \\
Mentoring relationship & 4.09 & $(.27)$ & $(.38)$ \\
composite & $(.37)$ & 4.46 & 4.25 \\
Mentoring role composite & 4.10 & $(.36)$ & $(.36)$ \\
& $(.51)$ & 4.42 & 4.44 \\
& & $(.47)$ & $(.35)$ \\
\hline
\end{tabular}


Figure 1. Mentee questionnaire topics and items.

NB: $\alpha=$ Cronbach's alpha for internal consistency for each domain. *These items were included in the Phase 2 questionnaires, based on feedback from the Phase 1 pilot.

\begin{tabular}{|c|c|}
\hline ACADEMIC SKILLS AND UNIVERSITY LIFE $(\alpha=.74)$ & SOCIAL RELATIONSHIPS AND SKILLS $(\alpha=.81)$ \\
\hline My confidence in my studies & Meeting new people \\
\hline Feeling positive about attending classes* & Making at least one close friend at university* \\
\hline Organisational skills* & My relationships with family members* \\
\hline Feeling connected to the university & My ability to make evening and weekend plans \\
\hline My relationships with members of academic staff in my department* & My social communication skills \\
\hline \multicolumn{2}{|c|}{ My awareness of other pastoral care services in the university (e.g. the counselling service) } \\
\hline Feeling comfortable in the university environment* & RELATIONSHIP WITH MENTOR $(\alpha=.88)$ \\
\hline \multirow[t]{2}{*}{ Feeling positive about my future employability* } & I have a positive relationship with my mentor* \\
\hline & I feel comfortable talking to my mentor* \\
\hline WELL-BEING $(\alpha=.93)$ & I trust my mentor* \\
\hline My coping skills & I find it easy to keep in contact with my mentor* \\
\hline Understanding my own emotions & EXAM SUPPORT $(\alpha=.91)$ \\
\hline Understanding other people's emotions* & My confidence in my exam performance* \\
\hline My self-esteem & Knowing ways to tackle my revision* \\
\hline Feeling positive about myself* & Revision timetabling* \\
\hline Feeling able to deal with unexpected events* & Exam related anxiety and/or stress* \\
\hline Feeling positive about the future in general* & $\begin{array}{l}\text { Practical exam arrangements (e.g. any special exam arrangements, or finding } \\
\text { information about exam times and locations)* }\end{array}$ \\
\hline
\end{tabular}


Figure 2. Mentor questionnaire topics and items.

NB: $\alpha=$ Cronbach's alpha for internal consistency for each domain. *These items were included in the Phase 2 questionnaires, based on feedback from the Phase 1 pilot.

\section{PERSONAL SKILLS $(\alpha=.33)$}

I have good listening skills

I have good problem solving skills

I enjoy helping others*

I am able to make a difference to others*

I have high self-esteem

\section{MENTORING RELATIONSHIP $(\alpha=.78)$}

Have a positive relationship with my mentee(s)*

Find it easy to stay in contact with my mentee(s)*

Provide support that will be valued by my mentee(s)*

Be able to make a difference to my mentee(s)*

Help my mentee(s) develop their independence*

Provide practical support and guidance to my mentee(s)*

Help my mentee(s) develop their academic skills*

Help my mentee(s) develop their social skills*

Help my mentee(s) develop their social relationships*

Help my mentee(s) increase their well-being*

\section{EXAM SUPPORT $(\alpha=.91)$}

My confidence in my exam performance*

Knowing ways to tackle my revision*

Revision timetabling*

Practical exam arrangements (e.g. any special exam arrangements, or finding information about exam times and locations) *

\section{MENTORING ROLE $(\alpha=.72)$}

Find it easy to organise my mentoring sessions*

Find it easy to find an appropriate location to meet my mentee(s)*

Be able to cope with the needs of my mentee(s)*

Not worry excessively about my mentee(s) outside of sessions*

Have sufficient support from the university for my role as a mentor*

Know where I can seek advice or information for my role as a mentor*

Have sufficient awareness of academic resources for student mentees in the university (e.g. the library)*

Have sufficient awareness of pastoral care resources for student mentees in the university (e.g. the counselling service)*

Have sufficient understanding of social communication disorders (e.g. Autism Spectrum Disorder)* Have sufficient understanding of mental health conditions (e.g. anxiety and depression) for my work as a mentor*

\section{UNIVERSITY COMMUNITY $(\alpha=.42)$}

Be a valuable part of the university student support systems*

Have enough contact with other mentors*

Be comfortable in the university environment*

Be well connected to the university

Be comfortable in the university environment*

Be well connected to the university 
Figure 3. Thematic map depicting central aspects of the mentoring process

NB: The central theme, Tailored partnerships, is shown in bold. This is linked to three main themes, Bridges, Personal relationship, and Empowerment, and their sub-themes.

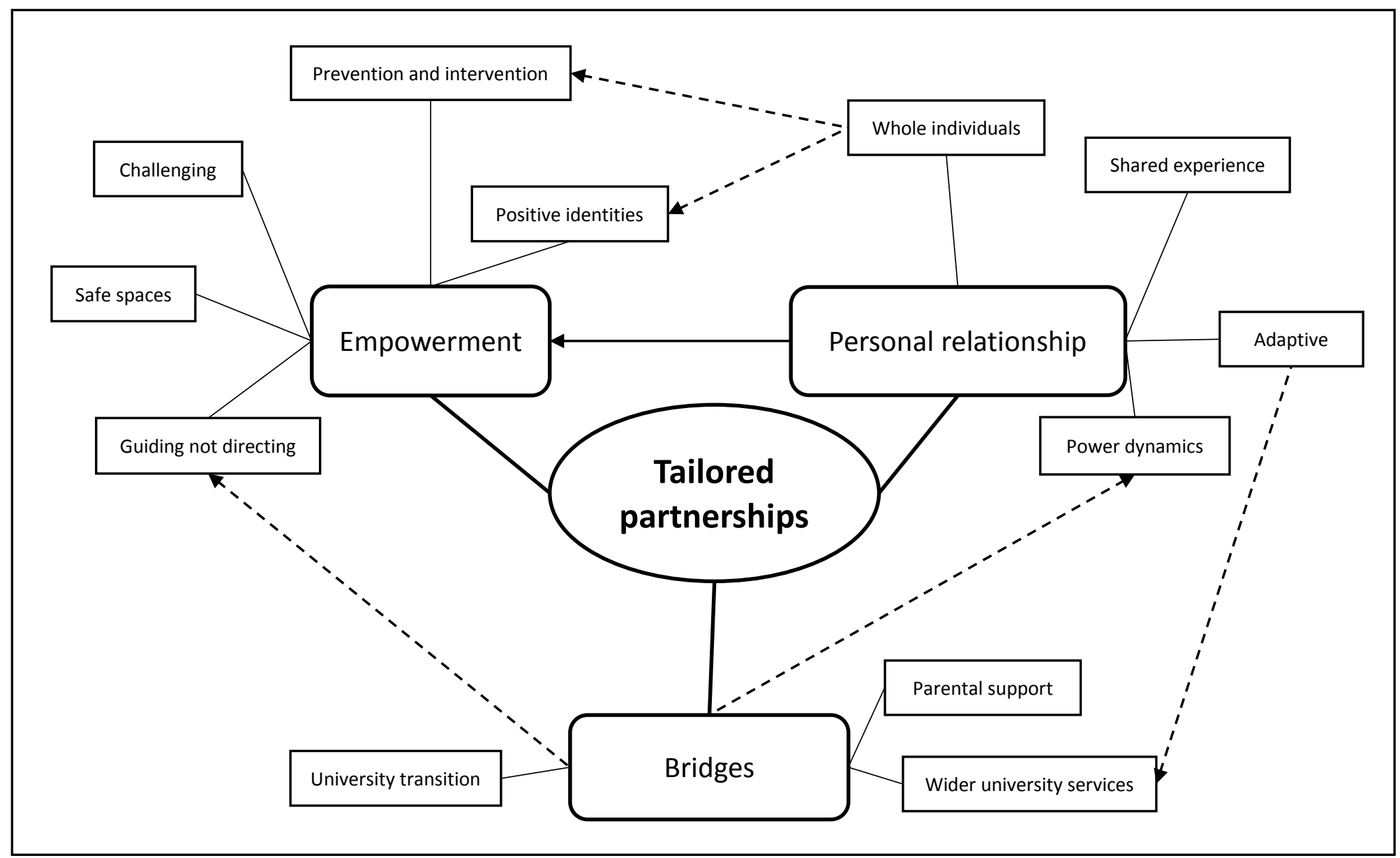

